\title{
Structural and Biochemical Features of Eimeria tenella Dihydroorotate Dehydrogenase, a Potential Drug Target
}

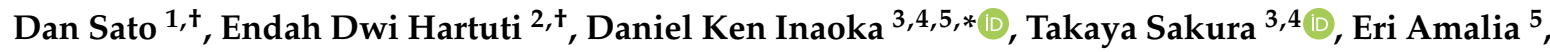 \\ Madoka Nagahama ${ }^{1}$, Yukina Yoshioka ${ }^{1}$, Naotoshi Tsuji ${ }^{6}$, Tomoyoshi Nozaki ${ }^{5}{ }^{\mathbb{D}}$, \\ Kiyoshi Kita ${ }^{4,5,7}$, Shigeharu Harada ${ }^{1}$, Makoto Matsubayashi ${ }^{8}$ and Tomoo Shiba ${ }^{1, *(D)}$ \\ 1 Department of Applied Biology, Graduate School of Science Technology, Kyoto Institute of Technology, \\ Matsugasaki, Sakyo-ku, Kyoto 606-8585, Japan; dsatodarby0415@hotmail.co.jp (D.S.); \\ qp.m.324@gmail.com (M.N.); yosioka_y02@yahoo.co.jp (Y.Y.); haradas2919@gmail.com (S.H.) \\ 2 Department of Parasitology, Institute of Tropical Medicine (NEKKEN), Nagasaki University, \\ 1-12-4 Sakamoto, Nagasaki 852-8523, Japan; endah.dwi08@yahoo.co.id \\ 3 Department of Molecular Infection Dynamics, Institute of Tropical Medicine (NEKKEN), \\ Nagasaki University, 1-12-4 Sakamoto, Nagasaki 852-8523, Japan; takaya.sakura@nagasaki-u.ac.jp \\ 4 School of Tropical Medicine and Global Health, Nagasaki University, 1-12-4 Sakamoto, \\ Nagasaki 852-8523, Japan; kitak@nagasaki-u.ac.jp \\ 5 Department of Biomedical Chemistry, Graduate School of Medicine, The University of Tokyo, 7-3-1 Hongo, \\ Bunkyo-ku, Tokyo 113-0033, Japan; amalia_eri@yahoo.co.id (E.A.); nozaki@m.u-tokyo.ac.jp (T.N.) \\ 6 Department of Parasitology, Kitasato University School of Medicine, 1-15-1 Kitasato, Minami-ku, \\ Sagamihara, Kanagawa 252-0374, Japan; tsujin@med.kitasato-u.ac.jp \\ 7 Department of Host-Defense Biochemistry, Institute of Tropical Medicine (NEKKEN), Nagasaki University, \\ 1-12-4 Sakamoto, Nagasaki 852-8523, Japan \\ 8 Division of Veterinary Science, Graduate School of Life and Environmental Sciences, Osaka Prefecture \\ University, 1-58 Rinku Orai Kita, Izumisano, Osaka 598-8531, Japan; matsubayashi@vet.osakafu-u.ac.jp \\ * Correspondence: danielken@nagasaki-u.ac.jp (D.K.I.); tshiba@kit.ac.jp (T.S.); \\ Tel.: +81-95-819-7230 (D.K.I.); Tel./Fax: +81-75-724-7541 (T.S.) \\ + These authors contributed equally to this paper.
}

Received: 20 October 2020; Accepted: 4 December 2020; Published: 7 December 2020

Abstract: Dihydroorotate dehydrogenase (DHODH) is a mitochondrial monotopic membrane protein that plays an essential role in the pyrimidine de novo biosynthesis and electron transport chain pathways. In Eimeria tenella, an intracellular apicomplexan parasite that causes the most severe form of chicken coccidiosis, the activity of pyrimidine salvage pathway at the intracellular stage is negligible and it relies on the pyrimidine de novo biosynthesis pathway. Therefore, the enzymes of the de novo pathway are considered potential drug target candidates for the design of compounds with activity against this parasite. Although, DHODHs from E. tenella (EtDHODH), Plasmodium falciparum (PfDHODH), and human (HsDHODH) show distinct sensitivities to classical DHODH inhibitors, in this paper, we identify ferulenol as a potent inhibitor of both EtDHODH and HsDHODH. Additionally, we report the crystal structures of EtDHODH and HsDHODH in the absence and presence of ferulenol. Comparison of these enzymes showed that despite similar overall structures, the EtDHODH has a long insertion in the $\mathrm{N}$-terminal helix region that assumes a disordered configuration. In addition, the crystal structures revealed that the ferulenol binding pocket of EtDHODH is larger than that of HsDHODH. These differences can be explored to accelerate structure-based design of inhibitors specifically targeting EtDHODH.

Keywords: coccidium; apicomplexa; Eimeria tenella; membrane protein; mitochondria; electron transport chain; dihydroorotate dehydrogenase; crystal structure; ubiquinone; inhibitor 


\section{Introduction}

Poultry industries are among the most important animal food resources, and their global production has tripled in a quarter-century (FAO, 2015). Hence, pathogens infecting chickens pose serious threats to world food security because such pathogens lead to reduced productivity. In particular, poultry coccidiosis has the greatest economic impact on productivity because of high infectivity and mortality [1], with an estimated annual worldwide economic loss of 2 billion dollars. More than 1200 species of Eimeria are known; these species typically have been defined based on host specificity [2]. Amongst the seven Eimeria species that are known to infect chickens, Eimeria tenella infection has the greatest impact in global agro-economics due to this pathogen's high virulence [3].

In currently used preventive therapies, vaccines with attenuated pathogens are encouraged due to the rise of drug resistance and public concerns for residue-free meat [3]. Although, the immune strategy can reduce the severity of diseases, it does not inhibit the infections, resulting in oocyst shedding in feces as potential sources of new infection and spread [3]. Hence, the development of new prophylactic modalities is indispensable for satisfactory prevention (or eradication) of the disease, e.g., suppressing the infections and possessing non-toxic and protozoan-specific effects.

Pathogen-specific mitochondrial pathways are validated drug targets. Such pathways have been explored for the development of new drugs against malaria, a disease that is caused by several Plasmodium parasites belonging to the phylum Apicomplexa. For example, the antimalarial drug atovaquone targets the Plasmodium falciparum mitochondrial electron transport chain (ETC) by binding at the $Q_{0}$ site of the cytochrome $b$ subunit of the $b c_{1}$ complex [4-6]. Inhibition of the $b c_{1}$ complex results, not only in the inhibition of oxygen respiration, but also the inhibition of all upstream ETC dehydrogenases, which comprise the non-proton-motive type II NADH dehydrogenase (NDH-2), succinate dehydrogenase (complex II), malate:quinone oxidoreductase (MQO), glycerol-3-phosphate dehydrogenase (G3PDH), and dihydroorotate dehydrogenase (DHODH) [7,8]. Complex II and MQO are components of the TCA cycle, and NDH-2 is required to re-oxidize NADH produced in mitochondrial metabolism, including the TCA cycle. Genetic validation conducted using P. berghei-infected mice or cultured P. falciparum has shown that NDH-2 [9,10] and complex II [11,12] are essential for oocyst development inside the mosquito, while MQO is required (at minimum) in the asexual blood stage $[7,13]$. Little is known about the role of G3PDH in apicomplexan parasites, although some studies have suggested a role for G3PDH in redox-balance, gluconeogenesis, and lipid biosynthesis [14,15]. DHODH catalyzes the oxidation of dihydroorotate and the reduction of an acceptor in the fourth and rate-limiting step of de novo biosynthesis of pyrimidines, molecules that serve as building blocks for DNA and RNA and are indispensable metabolites in all living organisms [16,17]. Animals commonly utilize two pathways for the biosynthesis of pyrimidines, de novo and salvage pathways. As also seen for Toxoplasma gondii, the genes encoding enzymes for pyrimidine de novo pathways seem to be conserved in the genome of E. tenella. Although a gene encoding uracil phosphoribosyltransferase (accession: AET50663), a key pyrimidine salvage pathway enzyme, can be found in the genome of E. tenella, the activity of this pathway appears to be negligible, at least in the intracellular stage, making this pathogen dependent on the de novo pathway to meet the cellular demand for pyrimidines [18-20]. Therefore, the enzymes of the de novo pathway are potential drug target candidates for the development of new compounds with activities against coccidian parasites.

Based on localization and electron acceptor, DHODHs are classified into two families: Family 1 members are soluble proteins localized to the cytosol, while family 2 members are membrane proteins localized to the inner mitochondrial membrane. Family 1 is further subdivided into family $1 \mathrm{~A}$ and family $1 \mathrm{~B}$, which use fumarate and $\mathrm{NAD}^{+}$(respectively) as electron acceptors $[17,21,22]$. Family 2 DHODH enzymes use respiratory quinones as electron acceptors [17,22-24]. The anti-proliferative agent leflunomide targets the quinone binding site of human DHODH (HsDHODH) and is used for the treatment of rheumatoid arthritis [25]. We recently reported that ascofuranone, an antibiotic isolated from Acremonium egiptiacum [26], and its synthetic derivatives are potent inhibitors of HsDHODH and exhibit selective cytotoxicity against cancer cells grown under conditions mimicking the tumor 
microenvironment (hypoxia and nutrient deprivation) [17]. Helicobacter pylori- and P. falciparum-specific DHODH inhibitors have been developed, and include compounds, such as intervenolin derivatives [23], and DSM265 [27], respectively. Recently, data from the Phase IIa trial of DSM265 indicated satisfactory results against the blood and liver stages of $P$. falciparum, suggesting the potential utility of this compound for the treatment and prevention of infection by this pathogen [27-29].

For structure-based drug design, the three-dimensional structure of a target protein is required. To our knowledge, the X-ray crystal structures of DHODHs, ligand-free and/or in complex with inhibitors, have been reported for human [17,30], rat [31,32], Escherichia coli [33], Streptococcus sp. mutans [34], Mycobacterium tuberculosis (PDB entry 4XQ6), Trypanosoma cruzi [16,22], T. brucei brucei [35,36], Leishmania donovani (PDB entry 3C61), and P. falciparum [37]. However, a potent inhibitor of family $2 \mathrm{DHODH}$ from any livestock parasite, and the crystal structure of the corresponding enzyme, have yet to be determined.

In this report, as a contribution toward the structure-based drug design of a new class of anti-coccidial agents, we have purified recombinant E. tenella DHODH (EtDHODH) and identified the enzyme's first nanomolar inhibitor. Moreover, the crystal structure of EtDHODH was determined in the absence and presence of the inhibitor. Comparative analysis with HsDHODH revealed important differences within the inhibitor binding pocket; such differences can be explored to design potential selective drugs for prevention of chicken coccidiosis.

\section{Materials and Methods}

\subsection{Sequence Analysis of E. tenella DHODH}

The protein sequences of DHODHs were analyzed using the ClustalW platform and the amino acid percentage identities calculated by the pairwise alignment tool from Jalview 2.9.0b2 software, according to developer's protocol (Figure S1) [38].

The atomic coordinates and structural factors have been deposited in the Protein Data Bank, www.odb.org (EtDHODH ligand-free form: 6AJ5, EtDHODH-ferulenol complex: 6AJE, HuDHODH ferulenol complex: 6IDJ).

\subsection{Expression and Purification of EtDHODH, PfDHODH, and $\mathrm{HsDHODH}$}

The sequence of the gene encoding a putative DHODH, as annotated in the genomic DNA of E. tenella strain Houghton (GenBank accession number CDJ37002), was confirmed by DNA sequencing of a complementary DNA (cDNA) prepared from E. tenella sporozoites [39]. Based on the deduced amino acid sequence, we synthesized a full-length of EtDHODH gene that was codon optimized for expression in E. coli; the resulting fragment was cloned into the pET19b plasmid vector (Novagen, Madison, WI, USA) via flanking NdeI and BamHI sites using a TaKaRa In-Fusion HD Cloning Kit (TaKaRa, Kyoto, Japan). The resulting plasmid (pET19b/EtDHODH) was transformed into the E. coli BL21 Star ${ }^{\mathrm{TM}}$ (DE3) strain (Invitrogen, Carlsbad, CA, USA) for protein expression. The transformant was grown in Luria-Bertani (LB) medium containing $50 \mu \mathrm{g} / \mathrm{mL}$ carbenicillin and $1 \%(w / v)$ glucose at $37^{\circ} \mathrm{C}$. The pre-culture $(30 \mathrm{~mL})$ was inoculated into $1 \mathrm{~L}$ of LB medium containing carbenicillin. When this culture reached the mid-log growth phase (optical density at $660 \mathrm{~nm}(\mathrm{OD} 660)=0.5)$, expression of the recombinant protein was induced by the addition of $1 \mathrm{mM}$ isopropyl $\beta$-D-thiogalactopyranoside (IPTG) and $20 \mu \mathrm{M}$ riboflavin at $18{ }^{\circ} \mathrm{C}$ for $18 \mathrm{~h}$. The cells were harvested by centrifugation at $8000 \times g$ for $20 \mathrm{~min}$ and stored at $-80{ }^{\circ} \mathrm{C}$ until use. The bacterial pellets collected from $6 \mathrm{~L}$ of culture were suspended in $40 \mathrm{~mL}$ of Buffer A (50 mM HEPES, pH 7.6, containing $300 \mathrm{mM} \mathrm{NaCl}, 10 \%(v / v)$ glycerol, $0.2 \mathrm{mM}$ sodium orotate) with complete mini EDTA-free Protease inhibitor cocktail (Roche, Basel, Switzerland). The suspension was passed through a French Pressure Cell three times at $200 \mathrm{MPa}$ to lyse the cells. The lysate was centrifuged at $20,000 \times g\left(4^{\circ} \mathrm{C}\right)$ to remove unbroken cells and inclusion bodies. The supernatant, which contained suspended membrane particles, was mixed with Triton X-100 to a final concentration of $1 \%(w / v)$, and further centrifuged for $90 \mathrm{~min}$ at $40,000 \times g\left(4{ }^{\circ} \mathrm{C}\right)$ to remove residual 
undissolved materials. The supernatant was applied to a HisTrap FF column (i.d. $0.7 \mathrm{~cm} \times 2.5 \mathrm{~cm}$, GE Healthcare, Chicago, IL, USA) equilibrated with Buffer A plus $10 \mathrm{mM}$ N,N-dimethylundecylamine N-oxide (UDAO, Santa Cruz Biotechnology, Dallas, TX, USA). After washing the column with the same buffer until the absorbance at $280 \mathrm{~nm}$ was negligible, recombinant EtDHODH protein was eluted stepwise with Buffer A containing 20, 100, 300, and $500 \mathrm{mM}$ imidazole. Fractions containing highly purified protein, as assessed by sodium dodecylsulfate polyacrylamide gel electrophoresis (SDS-PAGE), were pooled and the buffer was exchanged to Buffer B (50 mM HEPES, pH 7.6, containing $400 \mathrm{mM}$ $\mathrm{NaCl}, 30 \%(v / v)$ glycerol, $0.2 \mathrm{mM}$ sodium orotate, $10 \mathrm{mM}$ UDAO, and $1 \mathrm{mM}$ EDTA) using a centrifugal ultrafiltration device (Amicon Ultra-15, 50-kDa molecular weight cut-off; Merck Millipore, Burlington, MA, USA). The EtDHODH eluted at $300 \mathrm{mM}$ imidazole showed the highest purity (Figure S2) and was used for subsequent analysis. The purified protein was stored in $50 \%(v / v)$ glycerol at $-80{ }^{\circ} \mathrm{C}$ until use. Compared to the protein predicted from the genome, the final recombinant EtDHODH protein contained an additional $23 \mathrm{~N}$-terminal amino acid residues (MGHHHHHHHHHHSSGHIDDDDKH) that were derived from the expression vector.

Sequences encoding a truncated (lacking residues 1-157) P. falciparum DHODH (PfDHODH) and codon-optimized for $E$. coli expression were inserted into the pETSUMO expression vector to generate pETSUMO/PfDHODH and used to transform BL21 Star ${ }^{\mathrm{TM}}$ (DE3). Ten milliliters of pre-culture was used to inoculate into $500 \mathrm{~mL}$ of TB medium supplemented with $50 \mu \mathrm{g} / \mathrm{mL}$ kanamycin in an Ultra yield flask and cultured at $37^{\circ} \mathrm{C}$ with shaking at $250 \mathrm{rpm}$. After the OD600 reached 0.4-0.6, PfDHODH expression was induced by addition of $0.2 \mathrm{mM}$ IPTG, and the culture was incubated for a minimum of $16 \mathrm{~h}$ at $20{ }^{\circ} \mathrm{C}$ with shaking. All of the following purification steps were conducted at $4{ }^{\circ} \mathrm{C}$. The harvested cells were suspended in $20 \mathrm{~mL}$ of lysis buffer (50 mM HEPES-KOH, pH 7.6, $500 \mathrm{mM} \mathrm{NaCl,} 5 \mathrm{mM}$ imidazole, 20\% (v/v) glycerol, $0.25 \mathrm{mM}$ of phenylmethanesulfonyl fluoride (PMSF)) and broken by French Press at $180 \mathrm{MPa}$. Unbroken cells and debris were removed by centrifugation at $25,000 \times g$ for $20 \mathrm{~min}$ to obtain the extract. Triton X-100 was added to the extract to a final concentration of $1 \%(w / v)$; the mixture was stirred for $30 \mathrm{~min}$ and further centrifuged at 200,000 $\mathrm{g}$ for $90 \mathrm{~min}$. The resulting supernatant was mixed with $13 \mathrm{~mL}$ of Ni-NTA resin (Qiagen, Hilden, Germany) and rotated for $1 \mathrm{~h}$ at $10 \mathrm{rpm}$. After centrifugation at $1500 \times \mathrm{g}$ for $15 \mathrm{~min}$, the supernatant was discarded; the resin pellet was suspended in a minimal volume of supernatant and packed into a gravity-flow column. The column was washed consecutively with $60 \mathrm{~mL}$ of Buffer A (50 mM HEPES-KOH, pH 7.5, 300 mM $\mathrm{NaCl}, 10 \%(v / v)$ glycerol, $0.2 \mathrm{mM}$ orotate), $60 \mathrm{~mL}$ of Buffer A containing $0.05 \%(w / v) \mathrm{C}_{12} \mathrm{E}_{9}$, and $60 \mathrm{~mL}$ of Buffer A containing $5 \mathrm{mM}$ imidazole and 0.05\% (w/v) $\mathrm{C}_{12} \mathrm{E}_{9}$. Bound His6-SUMO-PfDHODH was eluted using $30 \mathrm{~mL}$ of Buffer A containing $300 \mathrm{mM}$ imidazole and $0.05 \%(w / v) \mathrm{C}_{12} \mathrm{E}_{9}$, and the eluate was collected at $1 \mathrm{~mL}$ per fraction. The protein content of each fraction was monitored at $280 \mathrm{~nm}$ using a Nanodrop spectrophotometer. The protein-containing fractions were pooled and concentrated using an Ultracel $50 \mathrm{kDa}$ MWCO device at 3500× $\mathrm{g}$ until the volume fell below $0.5 \mathrm{~mL}$. Buffer A was added to the device eluate to yield a final volume of $15 \mathrm{~mL}$, and the mixture was subjected to another round of concentration to reduce the imidazole concentration. To remove the His6-SUMO tag, one-twentieth amount of SUMO protease was added to the PfDHODH. The mixture was diluted with cleavage buffer (50 mM Tris $\mathrm{HCl}$ pH 8.0, $300 \mathrm{mM} \mathrm{NaCl}, 0.05 \%(w / v) \mathrm{C}_{12} \mathrm{E}_{9}, 0.2 \mathrm{mM}$ orotate) and incubated for $14.5 \mathrm{~h}$. Purification of His6-SUMO-tag-free native PfDHODH was achieved by loading the digestion mixture onto a 13-mL Ni-NTA column and collecting the flow-through. Finally, the purified PfDHODH was concentrated using an Ultracel $50 \mathrm{kDa}$ MWCO device at $3500 \times \mathrm{g}$. Ice-cold glycerol was added to the eluate to a final concentration of $50 \%(v / v)$, and this glycerol stock of purified PfDHODH was stored at $-30{ }^{\circ} \mathrm{C}$ until use. The purity of PfDHODH at each step of purification was evaluated by electrophoresis of aliquots on a SDS-PAGE.

A gene encoding $\mathrm{HsDHODH}$, without its mitochondrial targeting signal (residues 30-396), was inserted into pET19b at the BamHI and NdeI sites. The resulting plasmid was used to transform the BL21(DE3) $\triangle P y r D$ E. coli strain, and the enzyme was purified as described previously [17,22]. Briefly, a pre-culture of BL21(DE3) $\triangle P y r D / p E T 19 b H s D H O D H$ was prepared in $800 \mathrm{~mL}$ of $2 \times$ YT medium 
supplemented with $100 \mu \mathrm{g} / \mathrm{mL}$ of carbenicillin and $50 \mu \mathrm{g} / \mathrm{mL}$ of kanamycin, and incubated with shaking $\left(200 \mathrm{rpm}\right.$ ) at $25^{\circ} \mathrm{C}$ overnight. The pre-culture was centrifuged at $3000 \times g$ for $15 \mathrm{~min}$ at room temperature and the resulting pellet resuspended in $400 \mathrm{~mL}$ of fresh $2 \times$ YT medium supplemented with same concentrations of antibiotics. This E. coli suspension was inoculated into $7.8 \mathrm{~L}$ of $2 \times \mathrm{YT}$ prepared in a fermentor jar and used as the main culture. To avoid excessive foaming, $5 \mathrm{~mL}$ of antifoam (FS antifoam DB-110, Dow Corning, Midland, MI, USA) was added to the main culture, which was then incubated at $25^{\circ} \mathrm{C}$, with mixing at $600 \mathrm{rpm}$ and aeration at Level 7. When the OD600, which was monitored hourly, reached 1.0-1.2 (approximately $2 \mathrm{~h}$ ), IPTG was added to a final concentration of $1 \mu \mathrm{M}$. The culture then was further incubated for $16 \mathrm{~h}$ at $25^{\circ} \mathrm{C}$, with mixing at $600 \mathrm{rpm}$ and aeration Level 7 . All subsequent procedures were performed at $4{ }^{\circ} \mathrm{C}$. Cells were harvested by centrifugation at $4000 \times g$ for $15 \mathrm{~min}$, and the resulting pellet was suspended to a final volume of $210 \mathrm{~mL}$ in Buffer A ( $50 \mathrm{mM}$ HEPES-KOH, pH 7.6, $300 \mathrm{mM} \mathrm{NaCl}, 10 \%(v / v)$ glycerol, $0.2 \mathrm{mM}$ orotate) and broken by single passage in a French Press at $180 \mathrm{MPa}$. The resulting lysate was centrifuged at $20,000 \times \mathrm{g}$ for $10 \mathrm{~min}$ to obtain the extract. Triton X-100 was added into the extract to a final concentration of $1 \%(w / v)$, and the mixture was stirred for $30 \mathrm{~min}$ before centrifugation at $200,000 \times g$ for $75 \mathrm{~min}$. The resulting supernatant containing solubilized HsDHODH was combined with $10 \mathrm{~mL}$ of Talon ${ }^{\circledR}$ Superflow metal affinity resin (Clontech, Mountain view, CA, USA) pre-equilibrated with Buffer A and mixed for $1 \mathrm{~h}$. The protein-resin mixture was loaded onto a column, the flow-through fractions collected, and the resin washed consecutively with $100 \mathrm{~mL}$ of Buffer A and $200 \mathrm{~mL}$ Buffer A containing $10 \mathrm{mM}$ UDAO. The purified protein was eluted by application of a stepwise gradient of 16,30, and $160 \mathrm{mM}$ imidazole in Buffer A containing $10 \mathrm{mM}$ UDAO. The yellow active fractions were pooled and concentrated to a volume of less than $2 \mathrm{~mL}$ using an Ultracel $30 \mathrm{kDa}$ MWCO centrifugal device at $5000 \times g$, then filtered using an Ultrafree-CL Low Durapore $0.45-\mu \mathrm{m}$ membrane. Glycerol added to a final $50 \%(v / v)$ concentration, and the stock was stored at $-30^{\circ} \mathrm{C}$ until use.

\subsection{Enzyme Assays and Protein Concentration Determination}

All assays were performed using a Jasco V-660 spectrophotometer connected to a circulator and black quartz cuvettes in total $1 \mathrm{~mL}$ reaction volumes.

EtDHODH activity was measured in a reaction mixture containing $100 \mathrm{mM}$ HEPES, $\mathrm{pH}$ 7.6, $150 \mathrm{mM} \mathrm{NaCl}, 5 \%(v / v)$ glycerol, 0.05\% (w/v) Triton X-100, $120 \mu \mathrm{M}$ 2,6-dichlorobenzeneindophenol (DCIP), $14 \mu \mathrm{M}$ decylubiquinone (dUQ), and purified EtDHODH. After incubation at $37^{\circ} \mathrm{C}$ for $5 \mathrm{~min}$, the reaction was initiated by the addition of $L$-dihydroorotate $(\mathrm{DHO})$ to $200 \mu \mathrm{M}$, and the decrease in absorbance at $600 \mathrm{~nm}$ was monitored. The extinction coefficient of oxidized DCIP $600 \mathrm{~nm}$ is $21 \mathrm{~m}^{-1} \mathrm{~cm}^{-1}$.

Routine PfDHODH activity was assayed using an assay solution containing $100 \mathrm{mM}$ HEPES, pH 7.5, 5\% (v/v) glycerol, $150 \mathrm{mM} \mathrm{NaCl}, 0.05 \%(w / v)$ Triton X-100, $120 \mu \mathrm{M}$ DCIP, $15 \mu \mathrm{M}$ of dUQ, and the enzyme. The reaction was initiated by the addition of DHO to $200 \mu \mathrm{M}$, and the decrease in absorbance at $600 \mathrm{~nm}$ was monitored at $25^{\circ} \mathrm{C}$ as a measure of the consumption of oxidized DCIP.

$\mathrm{HsDHODH}$ activity was measured in an assay mixture containing $50 \mathrm{mM}$ Tris $\mathrm{HCl}, \mathrm{pH} 8.0$, $0.1 \%(w / v)$ Triton X-100, $2 \mathrm{mM} \mathrm{KCN}, 60 \mu \mathrm{M}$ dUQ, $120 \mu \mathrm{M}$ DCIP, and enzyme. The reactions were initiated by the addition of DHO to $500 \mu \mathrm{M}$. The decrease in absorbance at $600 \mathrm{~nm}$ was monitored at $25^{\circ} \mathrm{C}$ as a measure of the consumption of DCIP $[17,22]$.

Protein concentrations were determined by the Lowry method using bovine albumin as a standard [40].

\subsection{Screening of Inhibitors}

A focused library of approximately 200 compounds, comprising known inhibitors of ETC and known antiparasitic agents, was screened against EtDHODH, PfDHODH, and HsDHODH using 96-well plates; compounds were tested in triplicate at concentrations of 2.5 and $10 \mu \mathrm{M}$. The screening method was adapted from the previously reported end-point method used for HsDHODH and PfDHODH $[17,24]$. 
The assay mix for EtDHODH screening was composed of $100 \mathrm{mM}$ HEPES, pH 8.0, $50 \mathrm{mM} \mathrm{NaCl}$, 10\% (v/v) glycerol, 0.05\% (w/v) Triton X-100, $120 \mu \mathrm{M}$ DCIP, $18 \mu \mathrm{M}$ dUQ, and $360 \mathrm{ng} / \mathrm{mL}$ of purified EtDHODH. First, $193 \mu \mathrm{L}$ or $194.5 \mu \mathrm{L}$ of assay mix solution was transferred to each well of a 96-well plate containing (respectively) $2 \mu \mathrm{L}$ (final $10 \mu \mathrm{M}$ ) or $0.5 \mu \mathrm{L}$ (final $2.5 \mu \mathrm{M}$ ) per well of $1 \mathrm{mM}$ inhibitor stock solutions (columns 2 to 11). DMSO was added in columns 1 and 12; those columns were used as negative ( $0 \%$ inhibition) and positive controls $(100 \%$ inhibition, as a result of no substrate added, as noted below), respectively. The plates were mixed well, and background absorbance was recorded for $1 \mathrm{~min}$ at $600 \mathrm{~nm}$ and $25^{\circ} \mathrm{C}$ using a SpectraMax ${ }^{\circledR}$ Paradigm ${ }^{\circledR}$ Multi-Mode Microplate Reader (Molecular Device, San Jose, CA, USA). To initiate the reaction, $5 \mu \mathrm{L} /$ well of $5 \mathrm{mM}$ DHO was added (except for column 12, the positive control), the plate was mixed well, and the activity recorded for $20 \mathrm{~min}$. End-point measurement of the absorbance was performed after $20 \mathrm{~min}$, and EtDHODH inhibition was determined by calculating the inhibition (\%) relative to the activity in the negative and positive control columns. Hits were defined as compounds showing more than $50 \%$ inhibition at $2.5 \mu \mathrm{M}$.

The screening of inhibitors against PfDHODH was conducted using the same method as for EtDHODH, except that the assay mixture contained $100 \mathrm{mM} \mathrm{HEPES,} \mathrm{pH} \mathrm{7.5,} \mathrm{5 \%} \mathrm{(v/v)} \mathrm{glycerol,}$ $150 \mathrm{mM} \mathrm{NaCl}, 0.05 \%$ (w/v) Triton X-100, $120 \mu \mathrm{M}$ DCIP, $15 \mu \mathrm{M}$ dUQ, and $20 \mathrm{nM}$ of purified PfDHODH. The reactions were initiated by adding DHO to $200 \mu \mathrm{M}$. The activity was monitored as for EtDHODH.

The screening of inhibitors against HsDHODH was conducted using the same method as for EtDHODH, except that the assay mixture contained $50 \mathrm{mM}$ Tris- $\mathrm{HCl}, \mathrm{pH} 8.0,0.1 \%$ (w/v) Triton X-100, $2 \mathrm{mM}$ KCN, $60 \mu \mathrm{M}$ dUQ, $120 \mu \mathrm{M}$ DCIP and $5.85 \mathrm{nM}$ of purified HsDHODH. The reactions were initiated by adding DHO to $500 \mu \mathrm{M}$. The activity was monitored as for EtDHODH.

The quality of all screening conducted in this study was monitored by calculating the Z-factor, signal-to-background (S/B), signal-to-noise ( $/ \mathrm{N})$, signal window $(\mathrm{S} / \mathrm{W})$, and coefficient of variation (CV) for each assay plate, as previously described [41,42].

The ferulenol concentration that reduced the enzymatic activity by $50 \%\left(\mathrm{IC}_{50}\right)$ was determined by varying the inhibitor concentration and using a 96-well plate as described above.

\subsection{Crystallization and X-ray Diffraction Data Collection for EtDHODH}

Ligand-free crystals of EtDHODH suitable for X-ray analysis were obtained by the sitting-drop vapor-diffusion method at $20{ }^{\circ} \mathrm{C}$. EtDHODH at a concentration of $13 \mathrm{mg} / \mathrm{mL}$ in Buffer A (50 mM HEPES, pH 7.6, $400 \mathrm{mM} \mathrm{NaCl}, 30 \%(v / v)$ glycerol, $0.2 \mathrm{mM}$ sodium orotate, $10 \mathrm{mM}$ UDAO, 2\% $(w / v)$ $\mathrm{C}_{12} \mathrm{E}_{8}, 1 \mathrm{mM}$ EDTA) was mixed with an equal amount of the reservoir solution (100 mM HEPES, pH 7.0, 1.8 $\mathrm{M}$ triammonium citrate) to make a droplet of $0.5 \mu \mathrm{L}$ and equilibrated against $100 \mu \mathrm{L}$ reservoir solution. Crystals of EtDHODH-ferulenol complex were prepared by co-crystallization. A $0.5-\mu \mathrm{L}$ droplet of $11 \mathrm{mg} / \mathrm{mL}$ protein solution in Buffer C (10 mM HEPES, pH 7.6, $500 \mathrm{mM} \mathrm{NaCl}, 30 \%(w / v)$ glycerol, $0.2 \mathrm{mM}$ orotate, $10 \mathrm{mM}$ UDAO, $2 \%(w / v) \mathrm{C}_{12} \mathrm{E}_{8}, 1 \mathrm{mM}$ EDTA, $1 \mathrm{mM}$ ferulenol) was mixed with the same amount of reservoir solution and equilibrated against $100 \mu \mathrm{L}$ of the reservoir solution. X-ray diffraction experiments were performed on the BL44XU beamline at SPring-8 (Harima, Japan). Diffraction data were processed and scaled with the HKL-2000 software package [43].

\subsection{Structural Determination of EtDHODH with and without Inhibitor}

The initial structure of the inhibitor-free EtDHODH was determined by molecular replacement using the crystal structure of HsDHODH (PDB code: 3W7R), which has $49.6 \%$ amino acid identity with EtDHODH, as a search model. The crystal structure of the inhibitor-free EtDHODH was refined at $3.5 \AA$ resolution using REFMAC5 [44] to final $R_{\text {work }} / R_{\text {free values of } 0.272 / 0.359}$ (Table S1). The crystal structure of the EtDHODH-ferulenol complex was determined by molecular replacement using inhibitor-free EtDHODH as a search model. The crystal structure of EtDHODH-ferulenol complex was refined at $3.65 \AA$ resolution to final $R_{\text {work }} / R_{\text {free }}$ values of $0.221 / 0.303$ (Table S1). 


\subsection{Structure Determination of HsDHODH-Ferulenol Complex}

The HsDHODH-ferulenol complex crystals were obtained essentially as described previously $[17,22]$. X-ray diffraction data of HsDHODH-ferulenol complex crystal was collected at $100 \mathrm{~K}$ on the beamline BL-17A $(\lambda=0.98000 \AA$ A; ADSC Quantum 315r, Irving, TX, USA) at Photon Factory (Tsukuba, Japan). The data sets were processed and scaled using HKL-2000 [43]. The crystal structure of the HsDHODH-ferulenol complex was solved by molecular replacement using the refined protein coordinates of HsDHODH-mii-4-087 complex (PDB code 3W7R) [22] as a search model. MOLREP program [45] as implemented within CCP4 package [46] (http://www.ccp4.ac.uk/) was used for molecular replacement. Structural adjustments were made by iterative cycles of manual adjustments in COOT [47] and refinements by REFMAC5 [44]. The crystal structure of HsDHODH-ferulenol complex was refined to final $R_{\text {work }} / R_{\text {free }}$ values of $0.163 / 0.178$ (Table S1).

\section{Results}

\subsection{Sequence Analysis of EtDHODH}

The alignment as well as the percentage identity of EtDHODH and other family 2 DHODHs are shown in Figure S1. The N-terminal extension found in DHODHs from other apicomplexan parasites, such as P. falciparum, T. gondii, and Neospora caninum, is not conserved in EtDHODH (Figure S1). However, a long insertion from residues R217 to T252 is conserved among the DHODHs from the apicomplexan parasites listed in Figure S1. Moreover, residues essential for interaction with dihydroorotate showed higher levels of conservation than the ones required for interaction with ubiquinone. In addition, EtDHODH showed a higher degree of amino acid identity to mitochondrial DHODHs than to those from bacteria (Figure S1).

\subsection{Purification of DHODHs}

The DHODHs from E. tenella, P. falciparum, and human used in our study were successfully purified to homogeneity. The method used for purification of EtDHODH was adapted from the reported purification method for HsDHODH using Triton X-100 as the solubilizing detergent. EtDHODH, which was purified in a single step using nickel-affinity chromatography, showed specific activity of $32 \mu \mathrm{mol} / \mathrm{min} / \mathrm{mg}$ protein. In the case of PfDHODH, due to the low purification yield by the reported method, we developed a new expression system employing a His6-SUMO tag at the enzyme's N-terminus. Using this new construct, we purified a SUMO tag-free PfDHODH at yield of $73 \mathrm{mg}$ per liter of culture, with the purified enzyme showing specific activity of $20 \mu \mathrm{mol} / \mathrm{min} / \mathrm{mg}$ protein. The HsDHODH, which was purified essentially as described previously [17,22], exhibited a specific activity of $71 \mu \mathrm{mol} / \mathrm{min} / \mathrm{mg}$ protein.

\subsection{Screening for EtDHODH Inhibitors}

To identify an inhibitor of EtDHODH, we used a library, obtained from Nagasaki University, containing compounds focused on mitochondrial ETC inhibitors and known antiparasitic agents [41]. The screening method for EtDHODH was adapted from the reported HsDHODH method; we tested potential inhibitors at two concentrations $(2.5$ and $10 \mu \mathrm{M})$. The screening against EtDHODH was shown to be effective, yielding average values for the Z-factor, S/B, S/N, S/W, and CV of 0.866 , 1383, 351, 26.0, and 4.02\%, respectively. EtDHODH was not inhibited by classical inhibitors of ETC (such as rotenone, atpenin A5, siccanin, flutolanil, antimycin A, stigmatellin, myxothiazol, ascochlorin, and atovaquone) from various organisms, nor by known antiparasitic drugs (such as albendazole, ivermectin, chloroquine, artemisinin, morantel, and nitazoxanide) and potent PfDHODH inhibitor (DSM265). We identified 33 compounds that inhibited EtDHODH activity by more than 50\% when tested at concentrations of $2.5 \mu \mathrm{M}$. With the exception of ferulenol and its 3 derivatives thereof, the remaining 29 compounds all corresponded to ascofuranone derivatives. 


\subsection{Inhibitor Cross-Sensitivity of EtDHODH, PfDHODH, and HsDHODH}

Next, using the same library, we evaluated the cross-sensitivity of PfDHODH and HsDHODH to the same panel of inhibitors. Figure 1 shows the results of screening at concentrations of 2.5 and $10 \mu \mathrm{M}$ and compared among EtDHODH, PfDHODH, and HsDHODH. Our results clearly demonstrated that EtDHODH and PfDHODH did not show cross-sensitivity to inhibitors (Figure 1). However, we unexpectedly found that EtDHODH and HsDHODH share cross-sensitivity to two classes of compound: ferulenol, and some of ascofuranone derivatives. Although EtDHODH and HsDHODH showed cross-sensitivity to some of ascofuranone derivatives, there are several inhibitors specific for $\mathrm{HsDHODH}$ within this class of compounds (Figure S3).
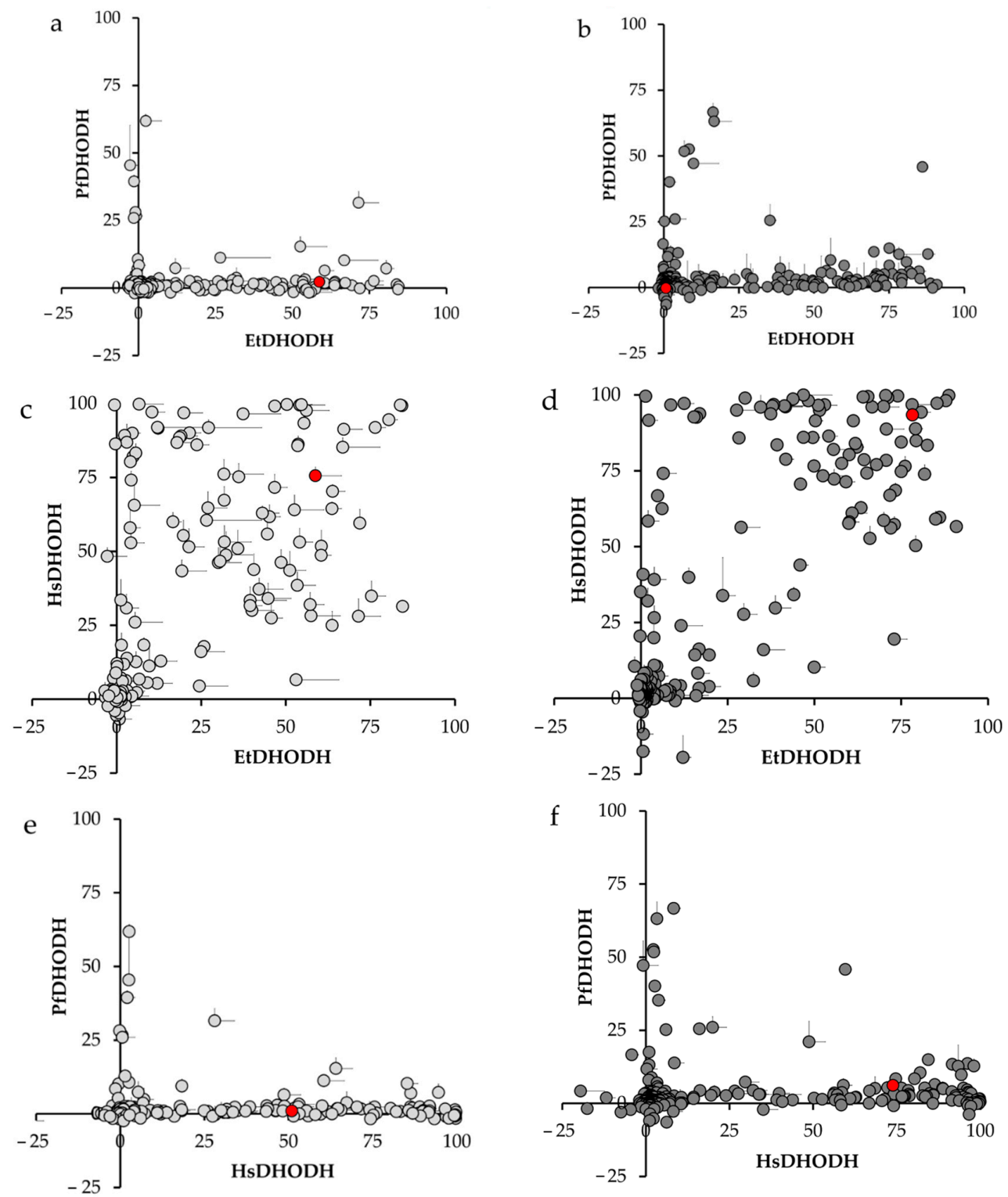

Figure 1. Cross-sensitivity of EtDHODH, PfDHODH, and $\mathrm{HsDHODH}$ to inhibitors at final concentrations of $2.5 \mu \mathrm{M}$ (a,c, and e, respectively) and $10 \mu \mathrm{M}$ (b,d, and $\mathbf{f}$, respectively). No significant cross-sensitivity was observed between EtDHODH and PfDHODH $(\mathbf{a}, \mathbf{b})$ or between PfDHODH and HsDHODH (e,f). However, cross-sensitivity was observed between EtDHODH and HsDHODH (c,d). The position of ferulenol is shown in red. Values plotted represents the average inhibition $(n=3)$. Only the positive value of SD was plotted for better representation. 


\subsection{Ferulenol is a Potent Inhibitor of EtDHODH and HsDHODH}

We previously identified ferulenol (Figure 2a) as the first potent and non-competitive inhibitor of P. falciparum $\mathrm{MQO}\left(\mathrm{IC}_{50}=57 \mathrm{nM}\right.$ ) (with respect to ubiquinone), and as the first competitive inhibitor of trypanosome alternative oxidase $\left(\mathrm{IC}_{50}=1.42 \mathrm{nM}\right.$ ) (with respect to ubiquinol) [41,48]. During our routine search for inhibitors of EtDHODH, we found that ferulenol also is an effective inhibitor of EtDHODH, exhibiting an $\mathrm{IC}_{50}$ (mean $\pm \mathrm{SD}$ ) of $483.1 \pm 56.5 \mathrm{nM}$ (Figure 2b). Moreover, the evaluation of the species-selectivity of ferulenol (Figure 2c) revealed that this compound also inhibited HsDHODH with an $\mathrm{IC}_{50}$ of $132.1 \pm 4.73 \mathrm{nM}$. In contrast, the enzymatic activity of PfDHODH was not inhibited by ferulenol, even at a concentration as high as $20 \mu \mathrm{M}$. To test whether EtDHODH shares cross-sensitivity to inhibitors of HsDHODH and PfDHODH, we assayed the effect of lapachol, brequinar, ferulenol and DSM265 on the enzymatic activities of EtDHODH, HsDHODH, and PfDHODH (Figure 3). As expected, lapachol and brequinar potently inhibited HsDHODH. However, neither compound exhibited significant inhibition of EtDHODH and PfDHODH (Figure 3). Similarly, DSM265 showed specific inhibition to PfDHODH. Ferulenol inhibited both of EtDHODH and HsDHODH enzymatic activities. These results indicated that EtDHODH does not share cross-sensitivity to classical DHODHs inhibitors, though ferulenol does inhibit the enzymatic activities of EtDHODH and HsDHODH.

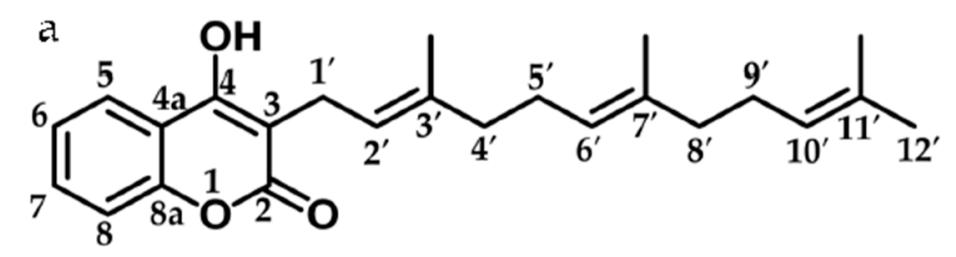

b

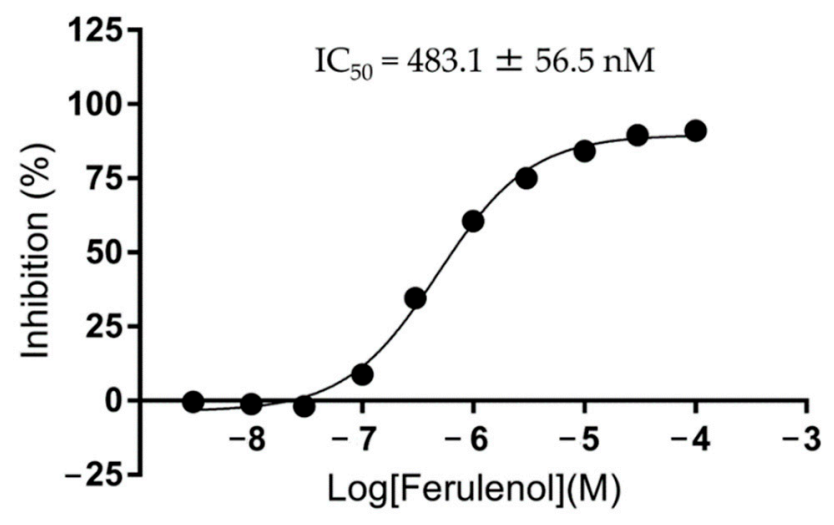

c

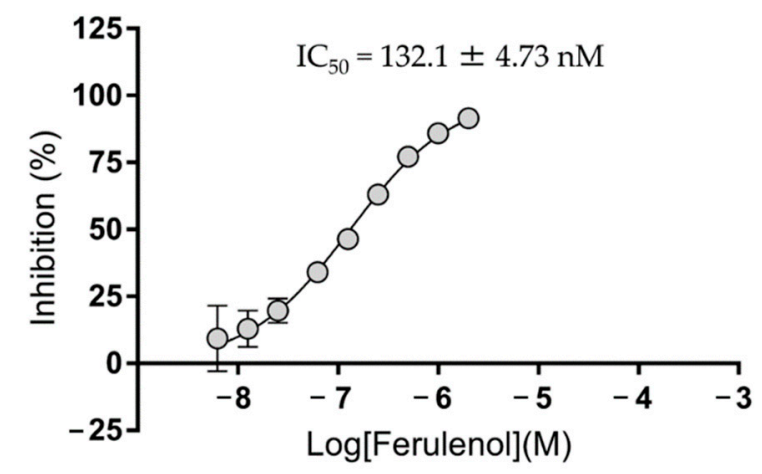

Figure 2. (a) Structure of ferulenol. Inhibition curves of ferulenol for EtDHODH (b) and HsDHODH (c). Values are plotted as mean $\pm \operatorname{SD}(n=4)$. 


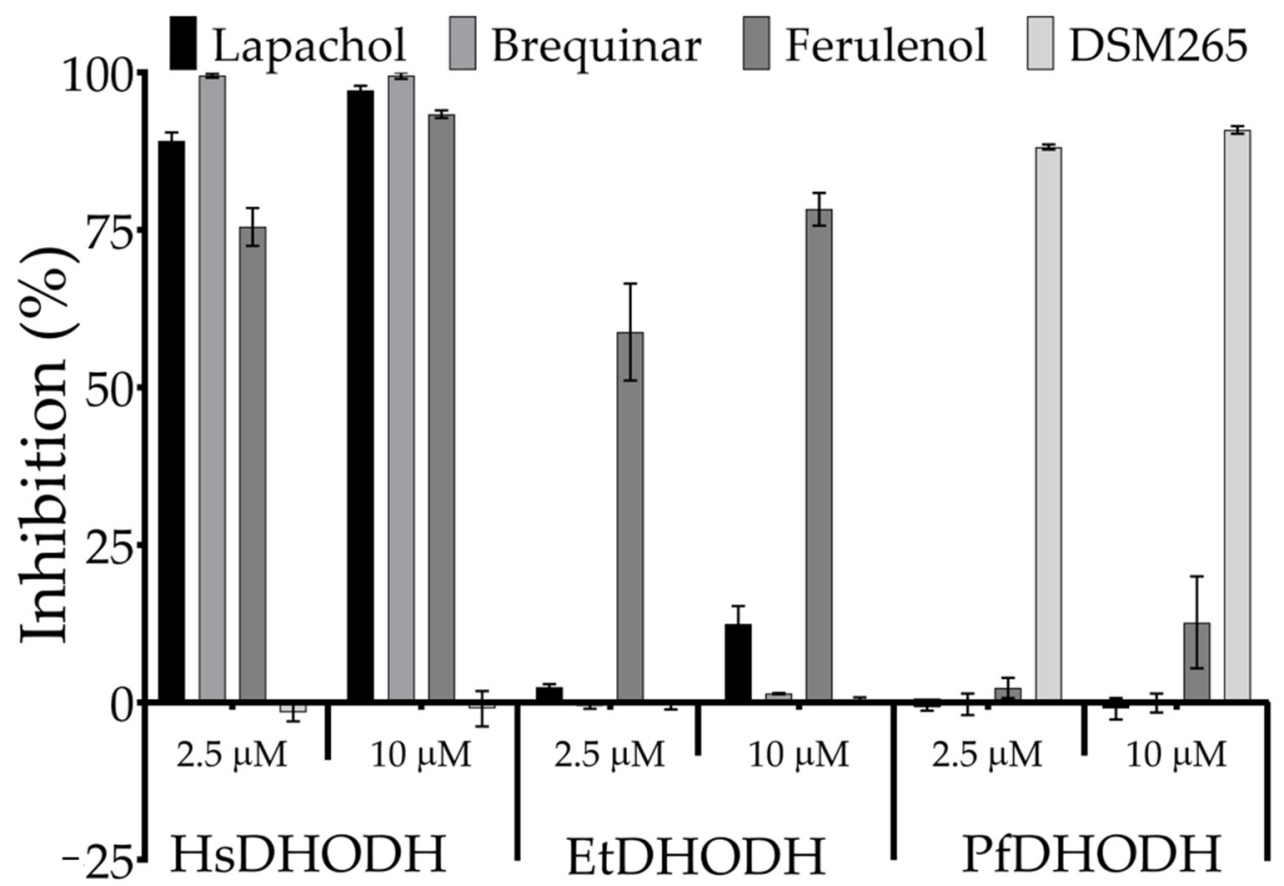

Figure 3. Cross-sensitivity of HsDHODH, EtDHODH, and PfDHODH to lapachol (black), brequinar (dark gray), ferulenol (light gray) and DSM265 (white). Lapachol and brequinar are positive controls for HsDHODH inhibition, whilst ferulenol and DSM265 is the positive control for EtDHODH and $\mathrm{PfDHODH}$, respectively. Values are plotted as mean $\pm \mathrm{SD}(n=4)$.

\subsection{Overall Structure of EtDHODH and Comparison to HsDHODH Structure}

The crystal structures of inhibitor-free EtDHODH and EtDHODH-ferulenol complex were determined at resolutions of $3.5 \AA$ and $3.65 \AA$, respectively (Figure 4). Both crystal forms contain four EtDHODH chains per asymmetric unit. The fact that; (i) there are no significant intermolecular interactions in either crystal structure, (ii) EtDHODH migrates at similar sizes with PfDHODH and HsDHODH, i.e., around $45 \mathrm{kDa}$, in high-resolution clear native electrophoresis (Figure S2) using dodeylmaltoside buffer (micelle size of $72 \mathrm{kDa}$ ) and visualized by CBB and DHODH activity staining collectively suggest that EtDHODH is functionally monomeric, consistent with other family 2 DHODHs such as those from human and P. falciparum. EtDHODH contains two domains connected by an extended loop and corresponding to a small $\mathrm{N}$-terminal domain ( $\mathrm{N}$-terminus to Ala31) and a large C-terminal domain (Asp43 to the C-terminus) (Figure 4a). The small N-terminal domain is the enzyme's membrane binding region, which forms two $\mathrm{N}$-terminal amphiphilic helixes $(\alpha \mathrm{A}$ and $\alpha \mathrm{B})$. The large domain has an $\alpha / \beta$-barrel fold with a central barrel of eight parallel $\beta$ strands $(\beta 1-\beta 8)$ surrounded by eight $\alpha$ helices $(\alpha 1-\alpha 8)$ (Figure $4 a)$. An additional pair of antiparallel $\beta$ strands, $\beta A$ and $\beta B$, are located at the bottom of the barrel (Figure 4a). The large domain of EtDHODH contains additional antiparallel $\beta$ strands $(\beta C, \beta D$, and $\beta E$ ) at the top of the barrel (Figure $4 a)$. The long insertion region of EtDHODH (residues 218-243 in the inhibitor-free structure and residues 217-239 in the ferulenol complex structure) is missing from the final structures due to the insertion sequences' poor electron density (Figure $4 a, b)$.

Although, the overall structures of both enzymes were similar, there were two marked differences, which were located at the $\mathrm{N}$-terminal helix region and at the long insertion region. In the ligand-free EtDHODH crystal structure, the electron density map of the N-terminal helix region $(\alpha \mathrm{A})$ was disordered, indicating the high flexibility of this region (Figure 5a). On the other hand, in the HsDHODH-ferulenol complex structure, the N-terminal region was clear and formed an extended $\alpha$-helix ( $\alpha$ A, Figure $5 b)$. Met43 and Leu48, residues located in the extended $N$-terminal $(\alpha \mathrm{A})$ region of $\mathrm{HsDHODH}$, interact with the isoprenyl tail of ferulenol (Figure $5 b$ ). Further, in the HsDHODH-ferulenol structure, two helices $(\alpha \mathrm{A}$ and $\alpha \mathrm{B})$ together form a V-shaped, membrane-associated region where 
the inhibitor is bound. The extended insertion region ( 35 residues), located between $\alpha 4$ and $\beta 5$ in EtDHODH (Figures $4 a$ and $5 a$ ), and the corresponding region in $\mathrm{HsDHODH}$ (Figure 5b), are located far from the active site and may not affect the binding of substrates or inhibitors to either enzyme.

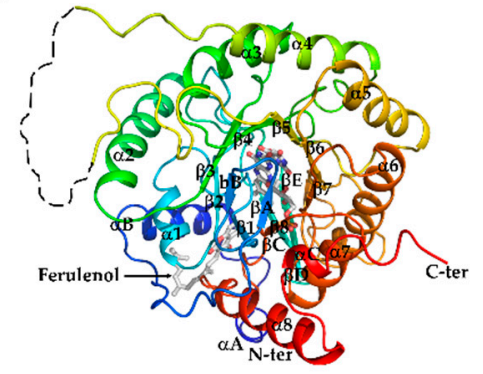

b

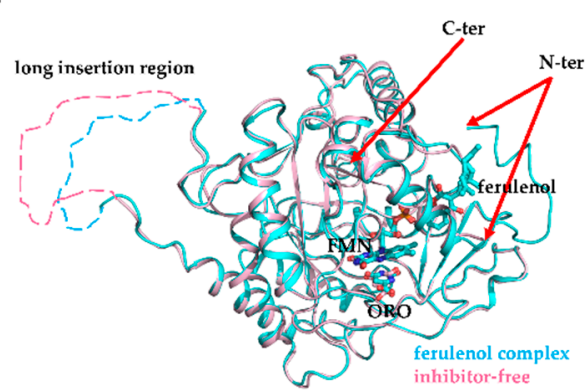

Figure 4. (a) Overall structure of EtDHODH. Cartoon model is colored in rainbow from blue ( $\mathrm{N}$ terminus; $\mathrm{N}$-ter) to red ( $\mathrm{C}$ terminus; $\mathrm{C}$-ter). The hydrophobic $\mathrm{N}$-terminal domain composed of two $\alpha$-helices is illustrated in blue $(\alpha \mathrm{A}$ and $\alpha \mathrm{B})$. The catalytic central barrel $\left((\alpha / \beta)_{8}\right.$ barrel) is composed of eight parallel $\beta$ strands ( $\beta 1-\beta 8)$ and surrounded by eight $\alpha$-helices $(\alpha 1-\alpha 8)$. Another $\alpha$ helices and $\beta$ strands are labeled $\alpha \mathrm{C}$ and $\beta \mathrm{A}$ to $\beta \mathrm{E}$, respectively. (b) Superimposed images of EtDHODH-ferulenol complex and inhibitor-free structures. The dashed dotted lines represent the long insertion loop for which an electron density map was not readily visible. Orotate (ORO), flavin mononucleotide (FMN) and ferulenol molecules are shown in the ball and stick models.

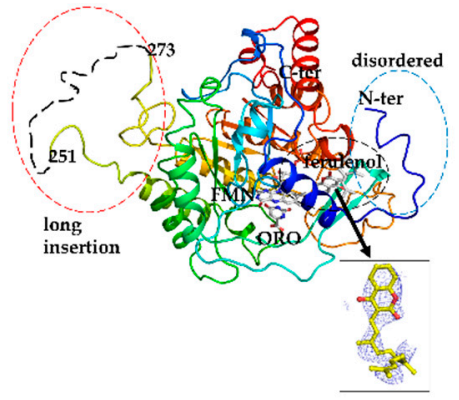

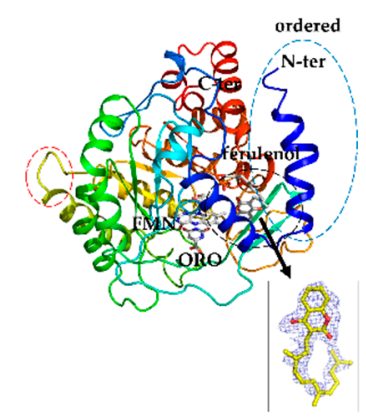

Figure 5. (a) Structure of EtDHODH in complex with ferulenol. The extended insertion and N-terminal $\alpha$ helix, seen only in EtDHODH, were disordered, and are highlighted in the dotted red circles. (b) Structure of HsDHODH in complex with ferulenol. Note that the long insertion and disordered $\mathrm{N}$-terminal regions (shown in the dotted blue circle) are not found in HsDHODH. The N-terminal V-shaped membrane-associated region is clearly visible in $\mathrm{HsDHODH}$ (blue helices) but not in EtDHODH. N-teminus and C-terminus are denoted as N-ter and C-ter, respectively. Ferulenol, flavin mononucleotide (FMN) and orotate (ORO) are highlighted in white ball-and-stick representation. The 2Fo -Fc electron density map (contoured at $1 \sigma$ ) of bound ferulenol (yellow stick) is highlighted as blue mesh in the right bottom in both figures.

\subsection{Recognition of Ferulenol by EtDHODH and HsDHODH}

In the EtDHODH-ferulenol complex crystal structure, the ferulenol molecule was bound to a hydrophobic cavity formed by the $\mathrm{N}$-terminal helices $(\alpha \mathrm{A}$ and $\alpha \mathrm{B}$ ); these $\mathrm{N}$-terminal helices are predicted to be the ubiquinone binding site (Figure 5a). The N-terminal region of EtDHODH-ferulenol complex (LLEVVYGLLPENFP), which is visible in the crystal structure, is stabilized by weak hydrophobic interactions with the His108, Tyr367, Arg368, and Arg375 residues. The aromatic ring of ferulenol is surrounded by Pro19, Ala22, His23, Val26, Phe65, Ile101, Tyr362, and Ile366 to form hydrophobic interactions (Figure 6a). Hydrogen bonds are formed only between the ferulenol $\mathrm{O} 4$ oxygen atom and the enzyme's Arg103 guanidino group, which defines the orientation of the aromatic ring (Figure 6a). 
The isoprenyl tail of ferulenol is surrounded by EtDHODH hydrophobic residues Pro17, Ala22, Met25, and Val26.
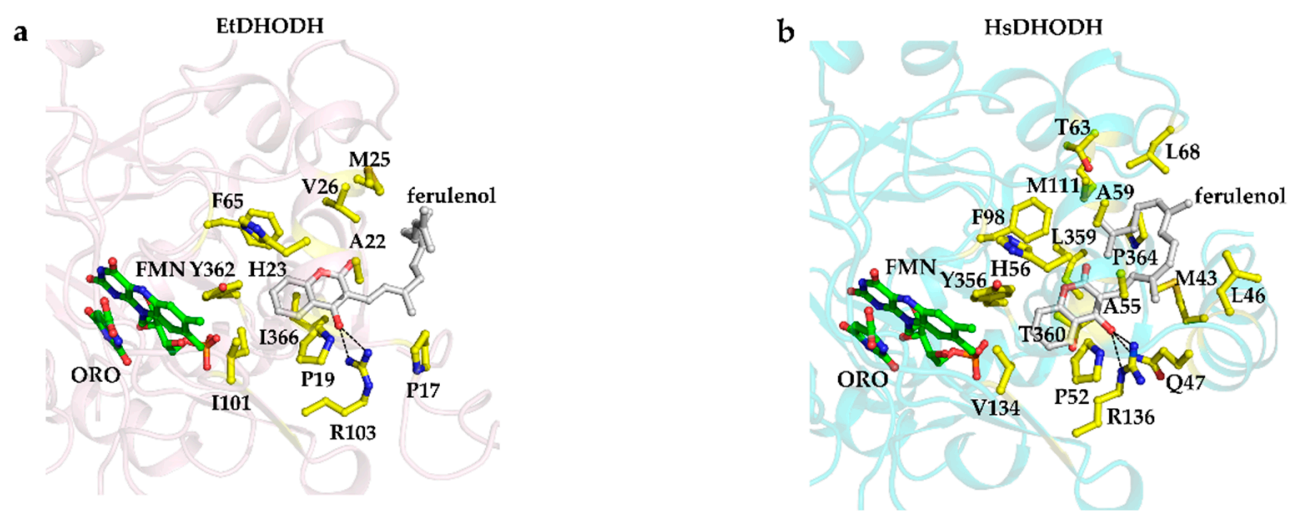

Figure 6. The binding mode of ferulenol (white) in $\operatorname{EtDHODH~(a)~and~} \mathrm{HsDHODH}(\mathbf{b})$. Residues located within approximately $4.0 \AA$ of bound ferulenol are shown in yellow ball-and-stick representation. Bound ORO and the cofactor FMN are shown as green ball-and-stick representation. The hydrogen bonds between ferulenol's O4 oxygen atom and Arg103 are shown as dashed lines.

From the co-crystal structures, we found that the binding mode of ferulenol is difference between EtDHODH and HsDHODH. The inhibitor is bound in the hydrophobic pocket located between the two $\mathrm{N}$-terminal amphiphilic helixes ( $\alpha \mathrm{A}$ and $\alpha \mathrm{B}$ ) in HsDHODH and in an equivalent region of EtDHODH (Figure 6a,b). However, as shown in Figure 6, ferulenol binds deeper in the hydrophobic pocket of HsDHODH compared to EtDHODH. The aromatic ring of ferulenol in the HsDHODH-ferulenol complex is surrounded by 10 residues (Gln47, Pro52, Ala55, His56, Ala59, Phe98, Val134, Arg136, Tyr356, and Thr360), forming many hydrophobic interactions (Figure 6b). The number of residues that are located within $4 \AA$ of the aromatic ring of ferulenol are reduced to 8 (Pro19, Ala22, His23, Val26, Phe65, Ile101, Tyr362, and Ile366) in EtDHODH (Figure 6a,b). For HsDHODH, in addition to Arg136 (corresponding to Arg103 from EtDHODH), the amide nitrogen atom of Gln47 forms an additional hydrogen bond to the $\mathrm{O} 4$ oxygen atom of ferulenol (Figure 6b). The isoprenyl tail of ferulenol bound to HsDHODH folds within the hydrophobic pocket and interacts with Met43, Leu46, Gln47, Ala55, Ala59, Thr63, Leu68, Phe98, Met111, Arg136, Leu359, and Pro364 through hydrophobic interactions (Figure $6 \mathrm{~b}$ ). On the other hand, the isoprenyl tail of ferulenol is bound facing the outside environment in EtDHODH with less interaction with amino acid residues. Consequently, the interactions of the isoprenyl tail of ferulenol are clearly tighter in HsDHODH than in EtDHODH (Figures 6 and 7), which could be the reason for the increased inhibition potency towards HsDHODH.

a

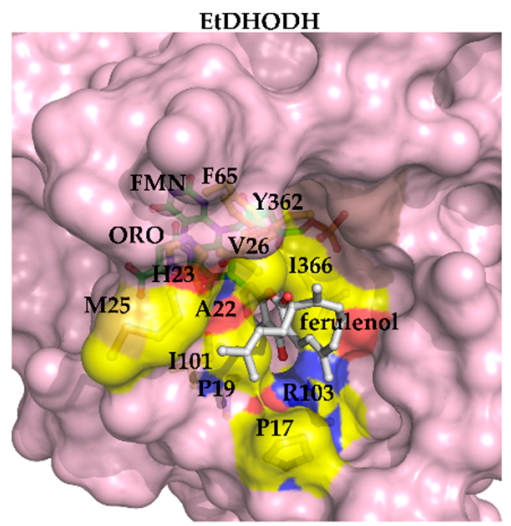

b

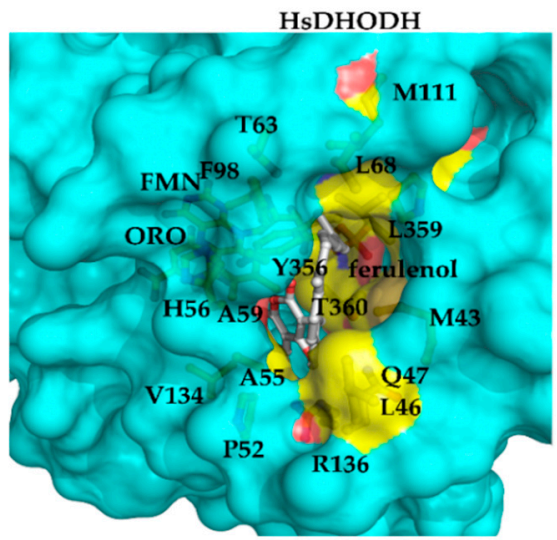

Figure 7. Surface representation showing the differences in the ferulenol (white) binding site between EtDHODH (a) and HsDHODH (b). Color codes are that same as those described in Figure 6. 


\section{Discussion}

The pyrimidine de novo biosynthesis pathway in apicomplexan parasites is an attractive target for drug development. Amongst the 6 enzymes of the de novo pathway, DHODH is the rate-limiting step and the key enzyme connecting pyrimidine biosynthesis to ETC at the level of ubiquinone. T. gondii can obtain pyrimidines through both the de novo and salvage pathways [49]. E. tenella has been reported to harbor an active pyrimidine de novo pathway, but to have only a negligible (or no) salvage pathway [19]. Other pathogens such as P. falciparum [50] and also H. pylori [51] lack the enzymes required for the salvage pathway, making those organisms highly dependent on the de novo pathway. This observation had led to the development of DSM265, a potent inhibitor of PfDHODH that has shown an excellent anti-plasmodial profile in Phase II clinical trials [27]. Separately, we recently reported the discovery of intervenolin and its derivatives as potent and specific H. pylori DHODH inhibitors; intervenolin shows excellent antibacterial activity in both in vitro and in vivo models [23]. Other enzyme from nucleotide biosynthesis such as dUTPase (deoxyuridine $5^{\prime}$-triphosphate nucleotidohydrolase, E.C.36.1.23), a house-keeping enzyme that catalyzes the hydrolysis of dUTP to PPi and dUMP, which in turn, is used as precursor dTMP biosynthesis, have been reported to be indispensable for parasite survival within erythrocytes and a druggable target [52-54].

Due to the high economic impact of coccidiosis in the poultry industry, we performed the first characterization of the mitochondrial ETC from E. tenella sporozoites [55]. At the sporozoite stage, this parasite showed very high activity for enzymes of the ETC, with the exception of DHODH. These data are consistent with the fact that sporozoites are in a non-dividing resting state, implying that the pyrimidine de novo pathway is inactive at this stage, resulting in extremely low DHODH activity. Indeed, previous reports have shown that sporozoites possess a low rate of RNA synthesis, which increased approximately 15-fold in the merozoite stage [20]. Accordingly, the activities of enzymes from the pyrimidine de novo pathway are reportedly low in the lysates of sporozoites [18]. As the E. tenella DHODH activity was barely detected in our previous study, we sought to determine whether the recombinant EtDHODH is functionally active. In the present study, we purified EtDHODH with a specific activity of $31 \mu \mathrm{mol} / \mathrm{min} / \mathrm{mg}$ protein $\left(K_{\text {cat }}=25.8 \mathrm{~s}^{-1}\right)$, a value higher than those reported for the P. falciparum orthologue [56,57]. Hence, these data provide the first direct evidence that EtDHODH is functionally active and strengthen the hypothesis that the pyrimidine de novo biosynthesis pathway is minimally or not active at the sporozoite stage.

As EtDHODH was not inhibited by established HsDHODH inhibitors, we tested the activity of EtDHODH in the presence of various ETC inhibitors, including rotenone, atpenin A5, antimycin A, flutolanil, ascofuranone, and ferulenol. Among these compounds, ferulenol was one of the potent inhibitor of EtDHODH. Recently, we reported that ferulenol is a potent inhibitor of P. falciparum MQO $\left(\mathrm{IC}_{50}=57 \mathrm{nM}\right)[41]$ and trypanosome alternative oxidase $\left(\mathrm{TAO} ; \mathrm{IC}_{50}=1.42 \mathrm{nM}\right)$. The crystal structure of TAO in complex with ferulenol was determined at $2.7 \AA$ resolution [48]. It also has been reported that ferulenol is a weak inhibitor of the rat mitochondrial respiratory enzyme succinate:ubiquinone reductase (SQR, $\left.\mathrm{IC}_{50}=17,000 \mathrm{nM}\right)$ [58] and an inhibitor of rat [59] and bacterial [60] vitamin K epoxide reductases (VKORs), with $\mathrm{IC}_{50} \mathrm{~s}$ of 98 and $200 \mathrm{nM}$, respectively. Therefore, ferulenol inhibits the activity of a variety of ETC enzymes and VKOR and may not be used in mammals. In this study, we revealed that EtDHODH is another target of ferulenol, with an $\mathrm{IC}_{50}$ value of $483 \mathrm{nM}$. Inhibitors of HsDHODH have been shown not to inhibit the DHODH activities of the P. falciparum [57] and E. coli [61] enzymes; similarly, PfDHODH inhibitors do not inhibit HsDHODH [62]. In the present work, we confirmed that ferulenol has no effect on PfDHODH enzyme activity, although the compound does exhibit potent inhibition of $\mathrm{HsDHODH}\left(\mathrm{IC}_{50}=132 \mathrm{nM}\right)$.

It is well-documented that the cross-sensitivity to inhibitors is very low among DHODHs from several species; this observation has been attributed to differences in the structure of the inhibitor binding pockets. Such differences were explored to design DSM265, a potent and specific PfDHODH inhibitor. Consistent with those results, EtDHODH and PfDHODH showed no cross-sensitivity to known HsDHODH inhibitors such as lapachol and brequinar, neither EtDHODH nor PfDHODH 
was inhibited by DSM265. Because ferulenol inhibited both of EtDHODH and HsDHODH, but not PfDHODH, we expected that the crystal structure of EtDHODH would reveal similarities between the inhibitor binding pockets of EtDHODH and HsDHODH. Interestingly, the binding mode of ferulenol were different between the two enzymes and the number of residues required to interact with the 4-hydroxycoumarin moiety of ferulenol are larger in HsDHODH than EtDHODH. In addition, interactions formed by the isoprenyl chain showed wider differences between the two enzymes. Collectively, these differences in binding mode of ferulenol could be the reason of its stronger inhibition over HsDHODH, compared to EtDHODH. It is important to note that, while EtDHODH and HsDHODH are both sensitive to ferulenol, potent HsDHODH inhibitors (lapachol, brequinar, ascofuranone and several ascofuranone derivatives) are ineffective against EtDHODH (Figure 3 and Figure S3). In order to reveal the structural determinant(s) for the insensitivity to ferulenol by PfDHODH, we have modelled the two binding modes of ferulenol onto the crystal structure of PfDHODH. Our analysis indicates that independently to the binding mode of ferulenol, the Phe188 from PfDHODH, located at the hydrophobic pocket, causes steric hindrance to the isoprenyl chain from ferulenol which makes its binding unfavorable (Figure S4). Similarly, when DSM265 was modelled onto the hydrophobic pocket of EtDHODH, several steric hindrance between the pentafluorosulfanyl moiety and the side chain from V26, M78 and F75 (Figure S5) were observed. These findings are consistent with the crystal structures, obtained in this study, and strongly suggests that the development of selective EtDHODH inhibitors can be achieved.

\section{Conclusions}

In this manuscript, we described the first recombinant expression system for coccidian DHODH and provided direct evidence that DHODH from E. tenella is functionally active. In addition, we identified ferulenol as the first nanomolar inhibitor of EtDHODH. Although, EtDHODH and PfDHODH showed no cross-sensitivity to HsDHODH inhibitors such as lapachol and brequinar, EtDHODH and HsDHODH were both sensitive to ferulenol. Moreover, we presented the first crystal structures of a coccidial DHODH (both ligand-free and bound to ferulenol), together with a structure for the HsDHODH-ferulenol complex. The results presented here showed that the ferulenol inhibits EtDHODH and HsDHODH by displaying different binding modes. These differences in interactions with ferulenol may help explain the differences in the $\mathrm{IC}_{50}$ values between EtDHODH and HsDHODH. Future studies should be addressed to understand whether or not ferulenol inhibits the chicken (host) enzyme once the method to obtain recombinant DHODH is established. Hence, our results should not be interpreted to justify the use of ferulenol for prevention and control of coccidiosis by the broilers, but to be exploited to accelerate the structure-based design of drugs targeting specifically coccidian DHODH.

Supplementary Materials: The following are available online at http://www.mdpi.com/2073-4425/11/12/1468/s1, Table S1. Statistics of data collection and structural refinement for EtDHODH and HsDHODH-ferulenol complex structures. Figure S1. Top: sequence alignment of amino acid sequences of DHODH from Eimeria tenella and other organisms. Figure S2. The purity and oligomeric state of EtDHODH in solution evaluated by SDS-PAGE and HrCNE, respectively. Figure S3. Differences in the sensitivity to ascofuranone derivatives between EtDHODH and HsDHODH. Figure S4. Model structure of ferulenol bound to PfDHODH. Figure S5. Superposed structure of DSM265 bound to PfDHODH and EtDHODH.

Author Contributions: Conceptualization, D.K.I., K.K., S.H., M.M. and T.S. (Tomoo Shiba); Data curation, D.K.I. and T.S. (Tomoo Shiba); Formal analysis, D.S., E.D.H., D.K.I., T.S. (Takaya Sakura), E.A., M.N., Y.Y. and T.S. (Tomoo Shiba); Funding acquisition, D.K.I., T.S. (Takaya Sakura), N.T., T.N., K.K., S.H., M.M. and T.S. (Tomoo Shiba); Investigation, D.S., E.D.H., E.A., M.N., Y.Y. and T.S. (Tomoo Shiba); Methodology, D.K.I., T.N., K.K. and T.S. (Tomoo Shiba); Project administration, D.K.I., N.T., T.N., K.K., S.H., M.M. and T.S. (Tomoo Shiba); Resources, D.K.I. and K.K.; Supervision, D.K.I., T.S. (Takaya Sakura), N.T., T.N., K.K., S.H., M.M. and T.S. (Tomoo Shiba); Visualization, D.K.I. and T.S. (Tomoo Shiba); Writing—original draft, D.S., E.D.H.; Writing—review and editing, D.K.I. and T.S. (Tomoo Shiba). All authors have read and agreed to the published version of the manuscript.

Funding: This work was supported in part by grants for Infectious Disease Control from the Science and Technology Research Partnership for Sustainable Development (SATREPS, no. 10000284 to K.K. and no. 14425718 to D.K.I. and T.N.) from the Agency for Medical Research and Development (AMED); a Grant-in-aid for Scientific 
Research on Priority Areas (no. 18073004 to K.K.); a Creative Scientific Research Grant (no. 18GS0314 to K.K.) from the Japan Society for the Promotion of Science; a Grant-in-aid from the Program for the Promotion of Basic and Applied Research for Innovations in Bio-Oriented Industry (BRAIN) (no. 26020A to S.H. and K.K.); Grants-in-aid for Scientific Research (B) (nos. 16K19114 and 19H03436 to K.K. and D.K.I.) and (C) (nos. 23570131 and 26234567 to To.S. and no. 19K07523 to D.K.I.); a Grant-in-aid for Early-Career Scientists (no. 19K16719 to Ta.S.); and a grant from The Leading Initiative for Excellent Young Researchers (LEADER) (no. 16811362 to D.K.I.) from the Japanese Ministry of Education, Science, Culture, Sports and Technology (MEXT). This work also was supported by a grant from the Japanese Initiative for Progress of Research on Infectious Diseases for Global Epidemics (no. JP18fm0208027 to D.K.I. and To.S.); and by Grants-in-aid for research on emerging and re-emerging infectious diseases from the Japanese Ministry of Health and Welfare (no. 17929833 to K.K. and T.N. and no. 20314363 to D.K.I. and T.N.).

Acknowledgments: We thank all of the staff members of beamlines BL44XU at SPring-8 and BL17A at Photon Factory (Proposal No. 2011G008) for their help with the collection of the X-ray diffraction data. The use of the synchrotron beamline BL44XU at SPring-8 was obtained through the Cooperative Research Program of the Institute for Protein Research, Osaka University (Proposal nos. 2015B6535, 2016A6635, and 2016B6635). Ascofuranone and ferulenol derivatives were kindly provided by Masaichi Yamamoto from the Institute of Mitochondria Sciences, Inc.

Conflicts of Interest: The authors declare no conflict of interest.

\section{References}

1. Allen, P.C.; Fetterer, R.H. Recent Advances in Biology and Immunobiology of Eimeria Species and in Diagnosis and Control of Infection with These Coccidian Parasites of Poultry. Clin. Microbiol. Rev. 2002, 15, 58-65. [CrossRef] [PubMed]

2. Chapman, H.D.; Barta, J.R.; Blake, D.; Gruber, A.; Jenkins, M.; Smith, N.C.; Suo, X.; Tomley, F.M. A selective review of advances in coccidiosis research. Adv. Parasitol. 2013, 83, 93-171. [CrossRef] [PubMed]

3. Witcombe, D.M.; Smith, N.C. Strategies for anti-coccidial prophylaxis. Parasitology 2014, 141, $1379-1389$. [CrossRef]

4. Birth, D.; Kao, W.C.; Hunte, C. Structural analysis of atovaquone-inhibited cytochrome bc1 complex reveals the molecular basis of antimalarial drug action. Nat. Commun. 2014, 5, 4029. [CrossRef]

5. Goodman, C.D.; Siregar, J.E.; Mollard, V.; Vega-Rodriguez, J.; Syafruddin, D.; Matsuoka, H.; Matsuzaki, M.; Toyama, T.; Sturm, A.; Cozijnsen, A.; et al. Parasites resistant to the antimalarial atovaquone fail to transmit by mosquitoes. Science 2016, 352, 349-353. [CrossRef]

6. Siregar, J.E.; Kurisu, G.; Kobayashi, T.; Matsuzaki, M.; Sakamoto, K.; Mi-ichi, F.; Watanabe, Y.; Hirai, M.; Matsuoka, H.; Syafruddin, D.; et al. Direct evidence for the atovaquone action on the Plasmodium cytochrome bc1 complex. Parasitol. Int. 2015, 64, 295-300. [CrossRef]

7. Ke, H.; Lewis, I.A.; Morrisey, J.M.; McLean, K.J.; Ganesan, S.M.; Painter, H.J.; Mather, M.W.; Jacobs-Lorena, M.; Llinas, M.; Vaidya, A.B. Genetic investigation of tricarboxylic acid metabolism during the Plasmodium falciparum life cycle. Cell Rep. 2015, 11, 164-174. [CrossRef]

8. Mogi, T.; Kita, K. Diversity in mitochondrial metabolic pathways in parasitic protists Plasmodium and Cryptosporidium. Parasitol. Int. 2010, 59, 305-312. [CrossRef]

9. Boysen, K.E.; Matuschewski, K. Arrested oocyst maturation in Plasmodium parasites lacking type II NADH:ubiquinone dehydrogenase. J. Biol. Chem. 2011, 286, 32661-32671. [CrossRef]

10. Ke, H.; Ganesan, S.M.; Dass, S.; Morrisey, J.M.; Pou, S.; Nilsen, A.; Riscoe, M.K.; Mather, M.W.; Vaidya, A.B. Mitochondrial type II NADH dehydrogenase of Plasmodium falciparum (PfNDH2) is dispensable in the asexual blood stages. PLoS ONE 2019, 14, e0214023. [CrossRef]

11. Hino, A.; Hirai, M.; Tanaka, T.Q.; Watanabe, Y.; Matsuoka, H.; Kita, K. Critical roles of the mitochondrial complex II in oocyst formation of rodent malaria parasite Plasmodium berghei. J. Biochem 2012, 152, 259-268. [CrossRef] [PubMed]

12. Tanaka, T.Q.; Hirai, M.; Watanabe, Y.; Kita, K. Toward understanding the role of mitochondrial complex II in the intraerythrocytic stages of Plasmodium falciparum: Gene targeting of the Fp subunit. Parasitol. Int. 2012, 61, 726-728. [CrossRef]

13. Niikura, M.; Komatsuya, K.; Inoue, S.I.; Matsuda, R.; Asahi, H.; Inaoka, D.K.; Kita, K.; Kobayashi, F. Suppression of experimental cerebral malaria by disruption of malate:quinone oxidoreductase. Malar. J. 2017, 16, 247. [CrossRef] 
14. Lian, L.Y.; Al-Helal, M.; Roslaini, A.M.; Fisher, N.; Bray, P.G.; Ward, S.A.; Biagini, G.A. Glycerol: An unexpected major metabolite of energy metabolism by the human malaria parasite. Malar. J. 2009, 8, 38. [CrossRef]

15. Olszewski, K.L.; Llinas, M. Central carbon metabolism of Plasmodium parasites. Mol. Biochem. Parasitol. 2011, 175, 95-103. [CrossRef] [PubMed]

16. Inaoka, D.K.; Sakamoto, K.; Shimizu, H.; Shiba, T.; Kurisu, G.; Nara, T.; Aoki, T.; Kita, K.; Harada, S. Structures of Trypanosoma cruzi dihydroorotate dehydrogenase complexed with substrates and products: Atomic resolution insights into mechanisms of dihydroorotate oxidation and fumarate reduction. Biochemistry 2008, 47, 10881-10891. [CrossRef] [PubMed]

17. Miyazaki, Y.; Inaoka, D.K.; Shiba, T.; Saimoto, H.; Sakura, T.; Amalia, E.; Kido, Y.; Sakai, C.; Nakamura, M.; Moore, A.L.; et al. Selective Cytotoxicity of Dihydroorotate Dehydrogenase Inhibitors to Human Cancer Cells Under Hypoxia and Nutrient-Deprived Conditions. Front. Pharm. 2018, 9, 997. [CrossRef] [PubMed]

18. Hill, B.; Kilsby, J.; Rogerson, G.W.; McIntosh, R.T.; Ginger, C.D. The enzymes of pyrimidine biosynthesis in a range of parasitic protozoa and helminths. Mol. Biochem. Parasitol. 1981, 2, 123-134. [CrossRef]

19. Khovanskikh, A.E. The assimilation by Eimeria tenella coccidia of DNA and RNA precursors from the host cell. Parazitologiia 1979, 13, 82-83.

20. LaFon, S.W.; Nelson, D.J. Purine metabolism in the intact sporozoites and merozoites of Eimeria tenella. Mol. Biochem. Parasitol. 1985, 14, 11-22. [CrossRef]

21. Inaoka, D.K.; Iida, M.; Hashimoto, S.; Tabuchi, T.; Kuranaga, T.; Balogun, E.O.; Honma, T.; Tanaka, A.; Harada, S.; Nara, T.; et al. Design and synthesis of potent substrate-based inhibitors of the Trypanosoma cruzi dihydroorotate dehydrogenase. Bioorg. Med. Chem. 2017, 25, 1465-1470. [CrossRef] [PubMed]

22. Inaoka, D.K.; Iida, M.; Tabuchi, T.; Honma, T.; Lee, N.; Hashimoto, S.; Matsuoka, S.; Kuranaga, T.; Sato, K.; Shiba, T.; et al. The open form inducer approach for structure-based drug design. PLoS ONE 2016, 11, e0167078. [CrossRef] [PubMed]

23. Ohishi, T.; Masuda, T.; Abe, H.; Hayashi, C.; Adachi, H.; Ohba, S.-I.; Igarashi, M.; Watanabe, T.; Mimuro, H.; Amalia, E.; et al. Monotherapy with a novel intervenolin derivative, AS-1934, is an effective treatment for Helicobacter pylori infection. Helicobacter 2018, 23, e12470. [CrossRef]

24. Pramisandi, A.; Dobashi, K.; Mori, M.; Nonaka, K.; Matsumoto, A.; Tokiwa, T.; Higo, M.; Kristiningrum; Amalia, E.; Nurkanto, A.; et al. Microbial inhibitors active against Plasmodium falciparum dihydroorotate dehydrogenase derived from an Indonesian soil fungus, Talaromyces pinophilus BioMCC-f.T.3979. J. Gen. Appl. Microbiol. 2020. [CrossRef]

25. Vyas, V.K.; Ghate, M. Recent developments in the medicinal chemistry and therapeutic potential of dihydroorotate dehydrogenase (DHODH) inhibitors. Mini Rev. Med. Chem. 2011, 11, 1039-1055. [CrossRef] [PubMed]

26. Araki, Y.; Awakawa, T.; Matsuzaki, M.; Cho, R.; Matsuda, Y.; Hoshino, S.; Shinohara, Y.; Yamamoto, M.; Kido, Y.; Inaoka, D.K.; et al. Complete biosynthetic pathways of ascofuranone and ascochlorin in Acremonium egyptiacum. Proc. Natl. Acad. Sci. USA 2019, 116, 8269-8274. [CrossRef] [PubMed]

27. Llanos-Cuentas, A.; Casapia, M.; Chuquiyauri, R.; Hinojosa, J.C.; Kerr, N.; Rosario, M.; Toovey, S.; Arch, R.H.; Phillips, M.A.; Rozenberg, F.D.; et al. Antimalarial activity of single-dose DSM265, a novel plasmodium dihydroorotate dehydrogenase inhibitor, in patients with uncomplicated Plasmodium falciparum or Plasmodium vivax malaria infection: A proof-of-concept, open-label, phase 2a study. Lancet Infect. Dis. 2018, 18, 874-883. [CrossRef]

28. Collins, K.A.; Rückle, T.; Elliott, S.; Marquart, L.; Ballard, E.; Chalon, S.; Griffin, P.; Möhrle, J.J.; McCarthy, J.S. DSM265 at 400 Milligrams Clears Asexual Stage Parasites but Not Mature Gametocytes from the Blood of Healthy Subjects Experimentally Infected with Plasmodium falciparum. Antimicrob. Agents Chemother. 2019, 63, e01837-18. [CrossRef] [PubMed]

29. Sulyok, M.; Ruckle, T.; Roth, A.; Murbeth, R.E.; Chalon, S.; Kerr, N.; Samec, S.S.; Gobeau, N.; Calle, C.L.; Ibanez, J.; et al. DSM265 for Plasmodium falciparum chemoprophylaxis: A randomised, double blinded, phase 1 trial with controlled human malaria infection. Lancet Infect. Dis. 2017, 17, 636-644. [CrossRef]

30. Liu, S.; Neidhardt, E.A.; Grossman, T.H.; Ocain, T.; Clardy, J. Structures of human dihydroorotate dehydrogenase in complex with antiproliferative agents. Structure 2000, 8, 25-33. [CrossRef] 
31. Deng, X.; Kokkonda, S.; El Mazouni, F.; White, J.; Burrows, J.N.; Kaminsky, W.; Charman, S.A.; Matthews, D.; Rathod, P.K.; Phillips, M.A. Fluorine modulates species selectivity in the triazolopyrimidine class of Plasmodium falciparum dihydroorotate dehydrogenase inhibitors. J. Med. Chem. 2014, 57, 5381-5394. [CrossRef] [PubMed]

32. Hansen, M.; Le Nours, J.; Johansson, E.; Antal, T.; Ullrich, A.; Loffler, M.; Larsen, S. Inhibitor binding in a class 2 dihydroorotate dehydrogenase causes variations in the membrane-associated N-terminal domain. Protein Sci. 2004, 13, 1031-1042. [CrossRef] [PubMed]

33. Norager, S.; Jensen, K.F.; Bjornberg, O.; Larsen, S.E. coli dihydroorotate dehydrogenase reveals structural and functional distinctions between different classes of dihydroorotate dehydrogenases. Structure 2002, 10, 1211-1223. [CrossRef]

34. Liu, Y.; Gao, Z.Q.; Liu, C.P.; Xu, J.H.; Li, L.F.; Ji, C.N.; Su, X.D.; Dong, Y.H. Structure of the putative dihydroorotate dehydrogenase from Streptococcus mutans. Acta Cryst. Sect. F Struct Biol. Cryst. Commun. 2011, 67, 182-187. [CrossRef]

35. Arakaki, T.L.; Buckner, F.S.; Gillespie, J.R.; Malmquist, N.A.; Phillips, M.A.; Kalyuzhniy, O.; Luft, J.R.; DeTitta, G.T.; Verlinde, C.L.M.J.; Van Voorhis, W.C.; et al. Characterization of Trypanosoma brucei dihydroorotate dehydrogenase as a possible drug target; structural, kinetic and RNAi studies. Mol. Microbiol. 2008, 68, 37-50. [CrossRef]

36. Kubota, T.; Tani, O.; Yamaguchi, T.; Namatame, I.; Sakashita, H.; Furukawa, K.; Yamasaki, K. Crystal structures of FMN-bound and FMN-free forms of dihydroorotate dehydrogenase from Trypanosoma brucei. FEBS Open Bio 2018, 8, 680-691. [CrossRef]

37. Deng, X.; Gujjar, R.; El Mazouni, F.; Kaminsky, W.; Malmquist, N.A.; Goldsmith, E.J.; Rathod, P.K.; Phillips, M.A. Structural plasticity of malaria dihydroorotate dehydrogenase allows selective binding of diverse chemical scaffolds. J. Biol. Chem. 2009, 284, 26999-27009. [CrossRef]

38. Waterhouse, A.M.; Procter, J.B.; Martin, D.M.; Clamp, M.; Barton, G.J. Jalview Version 2-A multiple sequence alignment editor and analysis workbench. Bioinformatics 2009, 25, 1189-1191. [CrossRef]

39. Matsubayashi, M.; Hatta, T.; Miyoshi, T.; Anisuzzaman; Sasai, K.; Shimura, K.; Isobe, T.; Kita, K.; Tsuji, N. High-throughput RNA sequencing profiles and transcriptional evidence of aerobic respiratory enzymes in sporulating oocysts and sporozoites of Eimeria tenella. Infect. Genet. Evol. 2013, 18, 269-276. [CrossRef]

40. Hartree, E.F. Determination of protein: A modification of the lowry method that gives a linear photometric response. Anal. Biochem. 1972, 48, 422-427. [CrossRef]

41. Hartuti, E.D.; Inaoka, D.K.; Komatsuya, K.; Miyazaki, Y.; Miller, R.J.; Xinying, W.; Sadikin, M.; Prabandari, E.E.; Waluyo, D.; Kuroda, M.; et al. Biochemical studies of membrane bound Plasmodium falciparum mitochondrial L-malate:quinone oxidoreductase, a potential drug target. Biochim. Biophys. Acta Bioenerg. 2018, 1859, 191-200. [CrossRef] [PubMed]

42. Wang, X.; Miyazaki, Y.; Inaoka, D.K.; Hartuti, E.D.; Watanabe, Y.I.; Shiba, T.; Harada, S.; Saimoto, H.; Burrows, J.N.; Benito, F.J.G.; et al. Identification of Plasmodium falciparum Mitochondrial Malate: Quinone Oxidoreductase Inhibitors from the Pathogen Box. Genes 2019, 10, 471. [CrossRef] [PubMed]

43. Otwinowski, Z.; Minor, W. Processing of X-ray diffraction data collected in oscillation mode. Methods Enzym. 1997, 276, 307-326. [CrossRef]

44. Murshudov, G.N.; Vagin, A.A.; Dodson, E.J. Refinement of macromolecular structures by the maximum-likelihood method. Acta Cryst. D Biol Cryst. 1997, 53, 240-255. [CrossRef] [PubMed]

45. Vagin, A.; Teplyakov, A. MOLREP: An Automated Program for Molecular Replacement. J. Appl. Crystallogr. 1997, 30, 1022-1025. [CrossRef]

46. Winn, M.D.; Ballard, C.C.; Cowtan, K.D.; Dodson, E.J.; Emsley, P.; Evans, P.R.; Keegan, R.M.; Krissinel, E.B.; Leslie, A.G.; McCoy, A.; et al. Overview of the CCP4 suite and current developments. Acta Cryst. D Biol. Cryst. 2011, 67, 235-242. [CrossRef] [PubMed]

47. Emsley, P.; Cowtan, K. Coot: Model-building tools for molecular graphics. Acta Cryst. D Biol. Cryst. 2004, 60, 2126-2132. [CrossRef]

48. Shiba, T.; Inaoka, D.K.; Takahashi, G.; Tsuge, C.; Kido, Y.; Young, L.; Ueda, S.; Balogun, E.O.; Nara, T.; Honma, T.; et al. Insights into the ubiquinol/dioxygen binding and proton relay pathways of the alternative oxidase. Biochim. Biophys. Acta Bioenerg. 2019, 1860, 375-382. [CrossRef]

49. Iltzsch, M.H. Pyrimidine salvage pathways in Toxoplasma gondii. J. Eukaryot. Microbiol. 1993, 40, $24-28$. [CrossRef] 
50. Cassera, M.B.; Zhang, Y.; Hazleton, K.Z.; Schramm, V.L. Purine and pyrimidine pathways as targets in Plasmodium falciparum. Curr. Top. Med. Chem. 2011, 11, 2103-2115. [CrossRef]

51. Copeland, R.A.; Marcinkeviciene, J.; Haque, T.S.; Kopcho, L.M.; Jiang, W.; Wang, K.; Ecret, L.D.; Sizemore, C.; Amsler, K.A.; Foster, L.; et al. Helicobacter pylori-selective antibacterials based on inhibition of pyrimidine biosynthesis. J. Biol. Chem. 2000, 275, 33373-33378. [CrossRef] [PubMed]

52. Pérez-Moreno, G.; Sánchez-Carrasco, P.; Rúiz-Pérez, L.; Johansson, N.; Müller, S.; Baragaña, B.; Hampton, S.; Gilbert, I.; Kaiser, M.; Sarkar, S.; et al. Validation of Plasmodium falciparum dUTPase as the target of 52-tritylated deoxyuridine analogues with anti-malarial activity. Malar. J. 2019, 18, 392. [CrossRef] [PubMed]

53. Hampton, S.E.; Baragaña, B.; Schipani, A.; Bosch-Navarrete, C.; Musso-Buendía, J.A.; Recio, E.; Kaiser, M.; Whittingham, J.L.; Roberts, S.M.; Shevtsov, M.; et al. Design, Synthesis, and Evaluation of 5'-Diphenyl Nucleoside Analogues as Inhibitors of the Plasmodium falciparum dUTPase. ChemMedChem 2011, 6, 1816-1831. [CrossRef] [PubMed]

54. Kumar, H.; Kehrer, J.; Singer, M.; Reinig, M.; Santos, J.M.; Mair, G.R.; Frischknecht, F. Functional genetic evaluation of DNA house-cleaning enzymes in the malaria parasite: dUTPase and Ap4AH are essential in Plasmodium berghei but ITPase and NDH are dispensable. Expert Opin. Ther. Targets 2019, 23, 251-261. [CrossRef]

55. Matsubayashi, M.; Inaoka, D.K.; Komatsuya, K.; Hatta, T.; Kawahara, F.; Sakamoto, K.; Hikosaka, K.; Yamagishi, J.; Sasai, K.; Shiba, T.; et al. Novel Characteristics of Mitochondrial Electron Transport Chain from Eimeria tenella. Genes 2019, 10, 29. [CrossRef] [PubMed]

56. Baldwin, J.; Farajallah, A.M.; Malmquist, N.A.; Rathod, P.K.; Phillips, M.A. Malarial dihydroorotate dehydrogenase. Substrate and inhibitor specificity. J. Biol. Chem. 2002, 277, 41827-41834. [CrossRef]

57. Hurt, D.E.; Widom, J.; Clardy, J. Structure of Plasmodium falciparum dihydroorotate dehydrogenase with a bound inhibitor. Acta Cryst. D Biol. Cryst. 2006, 62, 312-323. [CrossRef]

58. Lahouel, M.; Zini, R.; Zellagui, A.; Rhouati, S.; Carrupt, P.-A.; Morin, D. Ferulenol specifically inhibits succinate ubiquinone reductase at the level of the ubiquinone cycle. Biochem. Biophys. Res. Commun. 2007, 355, 252-257. [CrossRef]

59. Gebauer, M. Synthesis and structure-activity relationships of novel warfarin derivatives. Bioorg. Med. Chem. 2007, 15, 2414-2420. [CrossRef]

60. Li, W.; Schulman, S.; Dutton, R.J.; Boyd, D.; Beckwith, J.; Rapoport, T.A. Structure of a bacterial homologue of vitamin K epoxide reductase. Nature 2010, 463, 507-512. [CrossRef]

61. Chen, S.F.; Perrella, F.W.; Behrens, D.L.; Papp, L.M. Inhibition of dihydroorotate dehydrogenase activity by brequinar sodium. Cancer Res. 1992, 52, 3521-3527. [PubMed]

62. Phillips, M.A.; Rathod, P.K. Plasmodium dihydroorotate dehydrogenase: A promising target for novel anti-malarial chemotherapy. Infect. Disord Drug Targets 2010, 10, 226-239. [CrossRef] [PubMed]

Publisher's Note: MDPI stays neutral with regard to jurisdictional claims in published maps and institutional affiliations.

(C) 2020 by the authors. Licensee MDPI, Basel, Switzerland. This article is an open access article distributed under the terms and conditions of the Creative Commons Attribution (CC BY) license (http://creativecommons.org/licenses/by/4.0/). 